\title{
Clinical predictors for severe sepsis in patients with necrotizing fasciitis: an observational cohort study in northern Thailand
}

This article was published in the following Dove Press journal:

Infection and Drug Resistance

16 July 2015

Number of times this article has been viewed

\author{
Patcharin Khamnuan ${ }^{1,2}$ \\ Wilaiwan Chongruksut ${ }^{3}$ \\ Kijja Jearwattanakanok ${ }^{4}$ \\ Jayanton Patumanond ${ }^{5}$ \\ Apichat Tantraworasin ${ }^{3}$ \\ 'Clinical Epidemiology Program, \\ Faculty of Medicine, Chiang Mai \\ University, Chiang Mai, Thailand; \\ ${ }^{2}$ Department of Nursing, Phayao \\ Hospital, Phayao, Thailand; \\ ${ }^{3}$ Department of Surgery, Faculty of \\ Medicine, Chiang Mai University, \\ ${ }^{4}$ Department of Surgery, Nakornping \\ Hospital, Chiang Mai, Thailand; \\ ${ }^{5}$ Clinical Epidemiology Unit, Clinical \\ Research Center, Faculty of Medicine, \\ Thammasat University, Pathum Thani, \\ Thailand
}

Correspondence: Apichat Tantraworasin Department of Surgery, Faculty of Medicine, Chiang Mai University No.I I0, Inthavaroros Road, Sriphum Sub-district, Mueang Chiang Mai District, Chiang Mai Province, Chiang Mai 50200, Thailand Tel +66 53945767

Fax +6653946139

Emailohm_med@hotmail.com
Background: Necrotizing fasciitis (NF) is a life-threatening infection of skin and fascia. Its progress is extremely fast, with extensive necrosis. Delay in treatment, with subsequent huge soft tissue loss and associated severe sepsis, remains a major cause of death in the management of NF.

Objective: The aim of this study was to explore clinical characteristics that may be used to predict severe sepsis in patients with NF, in the context of routine clinical practice in northern Thailand.

Methods: A retrospective observational cohort study was conducted. The patient cohort in this study consisted of all patients who were diagnosed with NF by surgical or pathological confirmation. The follow-up period started with the admission date and ended with the discharge date. The clinical variables were collected from patients registered at three provincial hospitals in northern Thailand from 2009 to 2012 . The clinical predictors for severe sepsis were analyzed using multivariable risk regression.

Results: A total of 1,452 patients were diagnosed with NF, either with severe sepsis $(n=237$ [16.3\%]) or without severe sepsis $(n=1,215$ [83.7\%]). From the multivariable analysis, female sex (relative risk $[\mathrm{RR}]=1.51 ; 95 \%$ confidence interval $[\mathrm{CI}]=1.04-2.20)$, diabetes mellitus $(\mathrm{RR}=1.40$; 95\% CI $=1.25-1.58)$, chronic heart disease $(\mathrm{RR}=1.31 ; 95 \% \mathrm{CI}=1.15-1.49)$, hemorrhagic bleb ( $\mathrm{RR}=1.47 ; 95 \% \mathrm{CI}=1.32-1.63)$, skin necrosis $(\mathrm{RR}=1.45 ; 95 \% \mathrm{CI}=1.34-1.57)$, and serum protein $<6 \mathrm{~g} / \mathrm{dL}(\mathrm{RR}=2.67 ; 95 \% \mathrm{CI}=1.60-4.47)$ were all predictive factors for severe sepsis. Conclusion: The clinical predictors for severe sepsis in patients with suspicion of NF included female sex, diabetes mellitus, chronic heart disease, hemorrhagic bleb, skin necrosis, and serum protein $<6 \mathrm{~d} / \mathrm{dL}$. The risk ratio was much higher in patients with total protein less than $6 \mathrm{~g} / \mathrm{dL}$, which is associated with malnutrition. Therefore, provision of sufficient nutritional support and close monitoring for these clinical predictors may be beneficial to reduce morbidity and mortality.

Keywords: Necrotizing fasciitis, severe sepsis, clinical predictors

\section{Introduction}

Necrotizing fasciitis (NF) is a life-threatening infectious disease with a case-fatality rate worldwide of $15 \%-65 \% .{ }^{1-4}$ It is rare in developed countries, but it is a serious health problem in developing countries. NF has a high prevalence in northern Thailand, with an incidence of 7.45 cases per 100,000 in the general population, ${ }^{5}$ which is much higher than in developed countries $\left(0.40-1.30\right.$ cases per 100,000). ${ }^{6,7}$

$\mathrm{NF}$ is a rapidly progressing soft tissue infection, with extensive necrosis involving the skin, subcutaneous tissue, and superficial fascia or muscle. ${ }^{8-11}$ 
In early stages, no pathognomonic signs appear suggest the diagnosis of NF. The signs and symptoms of NF are wide ranging, including cellulitis, vesicles, bullae, edema, crepitus, erythema, and fever. Sometimes, patients are treated for simple cellulitis until rapid decomposition occurs. The complications are usually severe sepsis and death. The reported sepsis rate associated with NF remains at 24\%-30\%.,12,13

The identification of specific characteristic evidence and early diagnosis is essential to enable rapid treatment to reduce complications. ${ }^{14}$ Whenever the diagnosis and treatment are delayed or symptoms unidentified, postoperative morbidity or mortality will increase. ${ }^{15-17}$ Previous studies have demonstrated that risk factors for severe sepsis or death were sex, ${ }^{18}$ age, ${ }^{1,6,13,18}$ underlying disease, ${ }^{1,6,13,19}$ clinical presentation, ${ }^{1,13,18,19}$ microorganisms in the wound(s) or hemoculture, ${ }^{13}$ and time from admission to surgical intervention. ${ }^{8,18}$ Unfortunately, the time from admission to operation was not available in medical record data, therefore important variables such as delayed operation did not included in data analysis.

The aim of this study was to explore clinical characteristics that may be used to predict severe sepsis, in NF patients undergoing routine clinical treatment in northern Thailand. The findings may be incorporated into clinical evaluation in the future. Awareness and prevention of disease complications may reduce the incidence of severe sepsis.

\section{Patients and methods}

This study was a retrospective observational cohort study. Patient ascertained to have NF by surgical or pathological confirmation were the study cohort. A main purpose of the study was the exploration of potential prognostic factors predicting severe sepsis. NF was defined by the presence of necrosis of the subcutaneous tissue and fascia, with variable involvement of skin and muscle, and confirming operative findings by the surgeon. In the absence of histopathology, the diagnosis required the presence of gray necrotic fascia and necrosis detected during surgery.,16 The Infectious Diseases Society of America practice guidelines were used to diagnose NF patients in this cohort, mainly involving the history, and clinical signs and symptoms of the patients. ${ }^{20}$ Computed tomography (CT) scan and magnetic resonance imaging (MRI) were not used to diagnose infections or evaluate the patients before surgery because of its unavailability in provincial hospitals.

The patients were registered and treated at three provincial hospitals in Chiang Rai, Kamphaeng Phet, and Phayao, in northern Thailand, from 2009 to 2012. The patient charac- teristics studied included sex, age, body mass index (BMI), education, occupation, underlying diseases, wound appearance and site of wound. The vital signs and laboratory data were recorded at the time of admission, and 48-72 hours after admission. We clearly excluded all possible severe sepsis cases at admission to avoid incorporation bias. As well immortal time bias should be minimal in this study because the time that potential prognostic factors were collected was at the time of admission. This study aimed to explore factors at admission that predicted severe sepsis afterward, therefore, immortal bias should not have affected the results of this study.

Patients were assessed by emergency department physicians and treated with broad-spectrum antibiotics. All cases were evaluated, and all required surgical procedure. Treatments in this study were defined as surgical procedures in the operating room and included incision, drainage, debridement of the necrotic fascia or muscle, fasciotomy, and amputation. All debrided tissue was dissected, and tissue culture performed. The definition of sepsis was the presence of two or more of the following features of the Systemic Inflammatory Response Syndrome (SIRS) criteria, ${ }^{21}$ from a collection of clinical signs and laboratory investigations, as follows: fever (core temperature $>38.3^{\circ} \mathrm{C}$ ) or hypothermia (core temperature $<36^{\circ} \mathrm{C}$ ); heart rate $>90 /$ min or $>2$ standard deviations (SDs) above the normal value for age; tachypnea or partial pressure of carbon dioxide $\left(\mathrm{PCO}_{2}\right)<4.3 \mathrm{kPa}$; and leukocytosis (white blood cell [WBC] count $>12,000 /$ $\mathrm{mm}^{3}$ ) or leukopenia (WBC count $<4,000 / \mathrm{mm}^{3}$ ) or normal WBC count with $>10 \%$ immature forms and evidence of source infection causing the above. The study outcome was severe sepsis, which was defined as sepsis with at least one organ dysfunction, including: cardiovascular system (treated with dopamine $>5 \mathrm{mcg} / \mathrm{kg} / \mathrm{min}$ or other vasopressive drugs at any dose, if used to increase $\mathrm{BP}>1$ hour after adequate volume resuscitation); respiratory system (ratio of arterial oxygen partial pressure to fractional inspired oxygen $\left[\mathrm{PaO}_{2} /\right.$ FiO2] $<200$ ); renal system (urine output $<0.5 \mathrm{~mL} / \mathrm{kg} /$ hour for at least 2 hours after adequate volume resuscitation); coagulopathy (platelet count $<100,000$ cell $/ \mathrm{mm}^{3}$ or international normalized ratio [INR] $>1.5$ ); and metabolic acidosis (blood lactate level $>$ upper normal limit value). Determinants to outcome time started at admission date to discharge date (follow-up time). There were no cases lost to follow up in this cohort.

Patients were divided in two groups: with and without severe sepsis. The study design was prognostic descriptive research with a retrospective cohort. All enrolled patients 
were registered and treated at three provincial hospitals in Chiang Rai, Kamphaeng Phet, and Phayao province, in northern Thailand. The statistical analysis in this study included three-stage analysis as follows: step 1 involved the analysis of demographic and clinical characteristic patient data, carried out with descriptive statistics and comparing variables among groups with and without severe sepsis. Categorical data were expressed as count and percentage, and analyzed by Fisher's exact test. Continuous data were expressed as mean or median, with SD or interquartile range analyzed by Student's $t$-test or Wilcoxon rank sum test, depending on data distribution. In step 2, univariable analysis was carried out using a risk regression generalized linear model, with cluster hospitals used to identify the independent risk factors for severe sepsis, presented with risk ratio and 95\% confidence interval (CI). In step 3, clinically significant variables and statistically significant variables $(P$-value $<0.05)$ in the univariable analysis model were included in a multivariable risk regression analysis, with generalized linear model cluster hospitals and step-backward method used to identify the independent risk factors for severe sepsis. Presentation with $95 \% \mathrm{CI}$ and a $P$-value $\leq 0.05$ were considered statistically significant.

We decided to use a multiple imputation method for variables with $\geq 10 \%$ missing values (an acceptable missing values in general is up to $10 \%) .{ }^{22}$ We used logistic regression to estimate missing values for each variable, using STATA. A modest amount of missing formation is recommended for three to five multiple imputations $(<30 \%)^{23}$ and then estimate the whole model. After that, we compared results from a complete-case analysis and multiple imputations analysis. If the final model by multiple imputations gave the same results or had only a slightly different RR, we decided to report the result from the complete data set (case analysis).

Multicollinearity among variables in patients characteristics were considered during data analysis. The study flow of this study is shown in Figure 1.

This study was approved by the Ethics Committees of the Chiang Rai Prachianukroh Hospital and Faculty of Medicine, Chiang Mai University.

\section{Results}

A total of 1,452 eligible NF patients were included in this study. In all, 237 patients (16.3\%) had severe sepsis, and 1,215 patients $(83.7 \%)$ had no severe sepsis after treatment. A total of 237 patients had organ dysfunction, and 350 organs were involved as shown in Table 1. Microorganisms in blood and wound cultures are shown in Table 2. The number of positive and negative blood/wound culture was calculated based upon the number of patients where a blood/wound

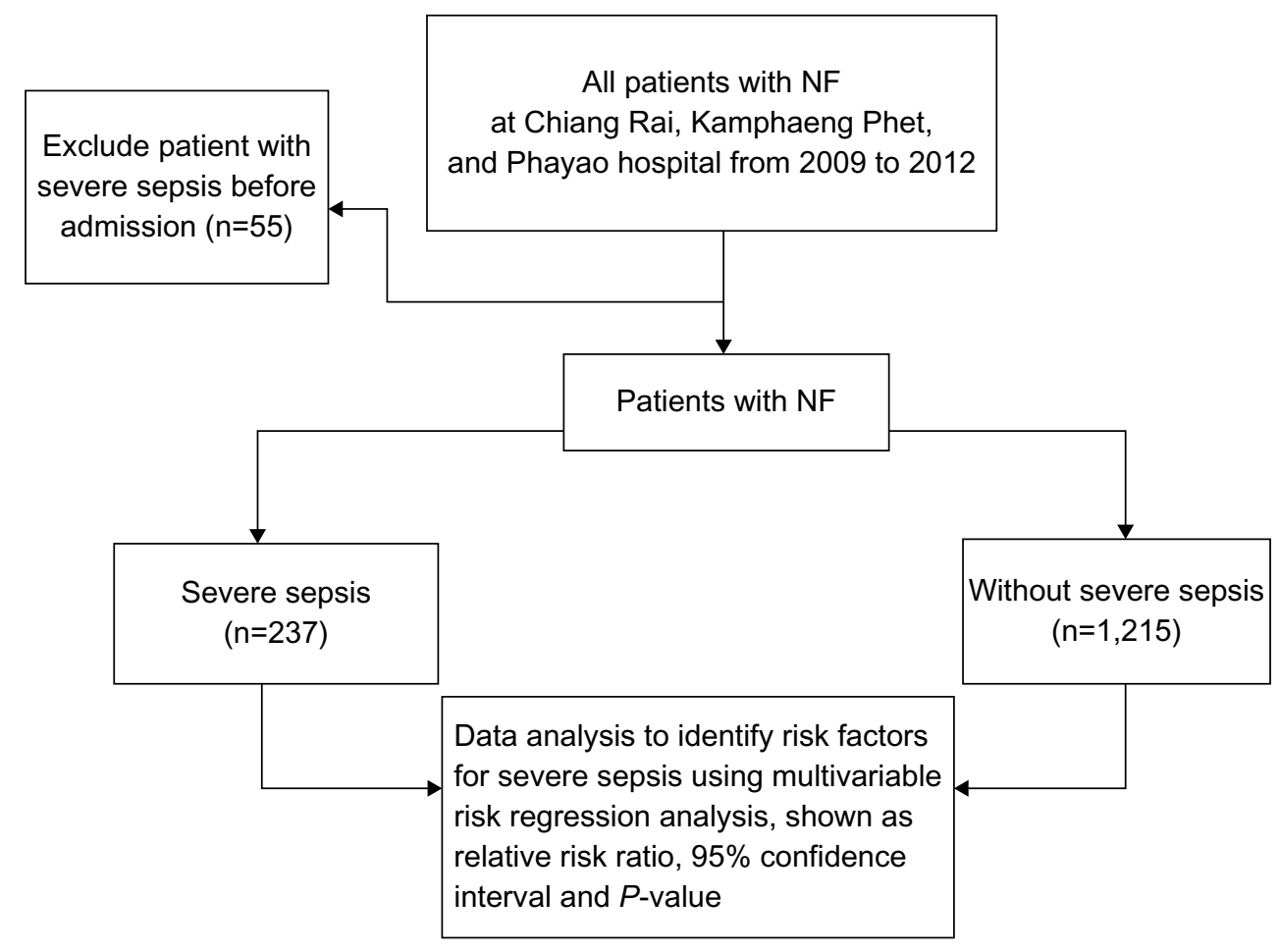

Figure I Study flow.

Abbreviation: NF, necrotizing fasciitis. 
culture was performed, eg, 69 patients of 400, 330 patients of 400,460 patients of 714, and 254 patients of 714. Blood culture and wound culture were not performed in 1,052 and 738 patients, respectively.

Streptococcus pyogenes was the most common grampositive organism in wound cultures, both in the severe sepsis group (49.2\%) and in the "without severe sepsis" group $(38.1 \%)$. Coagulase-negative staphylococcus was the most common gram-positive pathogen in blood cultures, both in the severe sepsis group (36.4\%) and without severe sepsis group (52\%). Overall, the percentage of $S$. pyogenes infection was $41.4 \%$ in the severe sepsis group and $36.3 \%$ in the without severe sepsis group. The overall percentage coagulase-negative staphylococcus infection was $25.3 \%$ in the severe sepsis group and $18.0 \%$ in the without severe sepsis group. Methicillin-resistant Staphylococcus aureus (MRSA) was found in $4.6 \%$ and $2.9 \%$ of the severe sepsis group and without severe sepsis group, respectively.

Pseudomonas aeruginosa was the most common gramnegative organism in blood cultures and wound cultures, and was found in $31.3 \%$ and $32.7 .5 \%$, respectively, of the severe sepsis group and in $37.5 \%$ and $17.8 \%$, respectively, of the without severe sepsis group. The overall percentage of $P$. aeruginosa infection was $32.4 \%$ in the severe sepsis group and $18.7 \%$ in the without severe sepsis group. Multidrug resistant Acinetobacter spp. were found in 2.8\% of the severe sepsis group and $1.0 \%$ of the without severe sepsis group. Extended spectrum $\beta$ lactamases (ESBL)-producing strains isolates of Escherichia coli and Klebsiella pneumonia were found in $2.1 \%$ and $1.4 \%$ in severe sepsis group and $4.6 \%$ and $2.1 \%$ in without severe sepsis group respectively. Sex, age, education, occupation, some underlying diseases (chronic heart disease, renal disease, hypertension, and gout), some of the wound characteristics (erythema and hemorrhagic bleb), severe pain, some laboratory results on admission (polymorphonuclear neutrophils [PMNs], creatinine, bicarbonate, and total protein), laboratory results at 48 and 72 hours (WBC, PMNs, creatinine, bicarbonate, total protein), some of the vital signs on admission (pulse,

Table I Organ dysfunction in patients with necrotizing fasciitis and severe sepsis

\begin{tabular}{ll}
\hline Organ involved & $\mathbf{n}(\%)$ \\
\hline Acute renal failure & $136(57.4)$ \\
Respiratory failure & $195(82.3)$ \\
Heart failure & $8(3.4)$ \\
CNS (delirium) & $11(4.6)$ \\
\hline
\end{tabular}

Notes: The data reflect 237 patients and 350 organs. Values are expressed as $n$ (\%). Abbreviation: CNS, central nervous system.
Table 2 Microorganisms in blood and wound cultures of patients with necrotizing fasciitis

\begin{tabular}{|c|c|c|c|c|}
\hline \multirow[t]{2}{*}{ Organism } & \multicolumn{2}{|c|}{ Severe sepsis } & \multicolumn{2}{|c|}{$\begin{array}{l}\text { Without severe } \\
\text { sepsis }\end{array}$} \\
\hline & Blood & Wound & Blood & Wound \\
\hline \multicolumn{5}{|l|}{ Gram-positive } \\
\hline Staphylococcus & $3(2.2)$ & $13(9.7)$ & $2(0.8)$ & $76(13.3)$ \\
\hline MRSA & $2(1.4)$ & $2(1.5)$ & $0(0.0)$ & $7(1.2)$ \\
\hline $\begin{array}{l}\text { Coagulase negative } \\
\text { staphylococcus }\end{array}$ & $8(5.7)$ & $14(10.7)$ & $13(5.1)$ & $31(5.4)$ \\
\hline Streptococcus pyogenes & $4(2.9)$ & $32(24.1)$ & $5(2.0)$ & $84(14.7)$ \\
\hline Other gram-positive & $5(3.6)$ & $4(3.1)$ & $5(2.0)$ & $22(3.9)$ \\
\hline \multicolumn{5}{|l|}{ Gram-negative } \\
\hline Acinetobacter spp. & $2(1.5)$ & $9(6.7)$ & $\mathrm{I}(0.4)$ & $27(4.7)$ \\
\hline MDR Acinetobacter spp. & $0(0.0)$ & $2(1.5)$ & $0(0.0)$ & $2(0.4)$ \\
\hline Citrobacter spp. & I (0.7) & $2(1.5)$ & I (0.4) & $16(2.8)$ \\
\hline Escherichia coli & $3(2.2)$ & $15(11.3)$ & $\mathrm{I}(0.4)$ & $33(5.8)$ \\
\hline E. coli (ESBLs) & I (0.7) & $2(1.5)$ & I (0.4) & $8(1.4)$ \\
\hline Klebsiella pneumoniae & $3(2.2)$ & $2(1.5)$ & I (0.4) & $31(5.5)$ \\
\hline K. pneumoniae (ESBLs) & $\mathrm{I}(0.7)$ & $\mathrm{I}(0.8)$ & $0(0.0)$ & $4(0.7)$ \\
\hline Pseudomonas aeruginosa & $5(3.6)$ & $18(13.4)$ & $3(1.2)$ & $33(5.8)$ \\
\hline Aeromonas hydrophila & $0(0.0)$ & $0(0.0)$ & $0(0.0)$ & $4(0.7)$ \\
\hline Other gram-negative & $0(0.0)$ & $4(3.0)$ & $0(0.0)$ & $27(4.7)$ \\
\hline
\end{tabular}

Notes: Of 1,452 patients, the blood culture was not done in 1,052 (72.5\%). Positive isolates were found in 69 patients (4.8\%), and no bacterium was found in 330 patients $(22.7 \%)$. Wound culture was carried out with 714 patients $(49.2 \%)$, and 460 patients showed positive isolated specimens (31.7\%); 254 patients (17.5\%) had negative wound culture. Values are expressed as $n(\%)$.

Abbreviations: ESBL, extended spectrum $\beta$ lactamase; MDR, multidrug resistant; MRSA, methicillin-resistant Staphylococcus aureus.

respiratory rate, and systolic and diastolic blood pressure), and the vital signs at 48-72 hours (body temperature, pulse, respiratory rate, and systolic and diastolic blood pressure) showed statistically significant differences between the groups, as shown in Table 3 and Table 4. The number of amputations in the severe sepsis group was significantly higher than that in the without severe sepsis group $(13.5 \%$ in the severe sepsis group and $7.8 \%$ in the without severe sepsis group) $(P=0.008)$.

The most common antibiotic used in both groups was a third-generation cephalosporin combined with clindamycin (34.2\% in the severe sepsis group and $33.7 \%$ in the without severe sepsis group); however, overall, broad-spectrum antibiotic use was only $53.2 \%$ in the severe sepsis group and $44.4 \%$ in the without severe sepsis group. In univariable analysis, broad-spectrum antibiotic use was significantly higher in the severe sepsis group; however, in multivariable analysis, there was no statistically significant difference.

In patients with severe sepsis and without severe sepsis, 165 of 237 patients $(90.2 \%)$ and 66 of 1,215 patients (97.1\%), respectively, died in hospital, and the entire 28-day mortality rate was 18 of 237 (9.8\%) and two of 1,215 (2.9\%), respectively, as shown in Table 4 . In the subgroup analysis, the number of females $\geq 60$ years was higher than for males 
Table 3 Demographic characteristics and clinical manifestations in patients with necrotizing fasciitis, with severe sepsis and without severe sepsis $(n=I, 452)^{*}$

\begin{tabular}{|c|c|c|c|}
\hline Characteristics & $\begin{array}{l}\text { Severe } \\
\text { sepsis } \\
(n=237)\end{array}$ & $\begin{array}{l}\text { Without } \\
\text { severe sepsis } \\
(n=I, 2 \mid 5)\end{array}$ & $P$-value \\
\hline Sex & & & 0.027 \\
\hline Male & II 8 (49.8) & $700(57.7)$ & \\
\hline Female & $119(50.2)$ & $514(42.3)$ & \\
\hline Age (years) & & & $<0.001$ \\
\hline$<60$ & 77 (32.9) & $594(49.3)$ & \\
\hline$\geq 60$ & $157(67.1)$ & $6 \mathrm{II}(50.7)$ & \\
\hline BMI & & & 0.668 \\
\hline$\leq 18.50$ & $27(13.1)$ & $162(14.9)$ & \\
\hline$|8.5|-29.99$ & I6I (78.2) & $844(77.6)$ & \\
\hline$\geq 30.00$ & $18(8.7)$ & $81(7.5)$ & \\
\hline Education & & & $<0.001$ \\
\hline No education & $135(57.2)$ & $483(39.8)$ & \\
\hline Primary education & $97(4 I . I)$ & $648(53.4)$ & \\
\hline Secondary education & $4(1.7)$ & $56(4.6)$ & \\
\hline Bachelor's degree and more & $0(0.0)$ & $26(2.2)$ & \\
\hline Occupation & & & 0.010 \\
\hline Elderly who stays at home & $129(54.4)$ & $537(44.2)$ & \\
\hline Farmers/laborers & $101(42.6)$ & $612(50.4)$ & \\
\hline Officials & $7(3.0)$ & $65(5.4)$ & \\
\hline \multicolumn{4}{|l|}{ Underlying disease } \\
\hline Diabetes & $70(29.5)$ & $308(25.4)$ & 0.195 \\
\hline Heart disease & $29(12.3)$ & $6 \mathrm{I}(5.0)$ & $<0.001$ \\
\hline Renal disease & $13(5.5)$ & $30(2.5)$ & 0.019 \\
\hline Cirrhosis & $14(5.9)$ & $42(3.5)$ & 0.094 \\
\hline Hypertension & $107(45.2)$ & $406(33.4)$ & 0.001 \\
\hline Gout & $39(16.5)$ & $100(8.3)$ & $<0.001$ \\
\hline Chronic alcoholism & $40(16.9)$ & $185(15.2)$ & 0.556 \\
\hline \multicolumn{4}{|l|}{ Wound appearance } \\
\hline Soft tissue swell & $193(81.4)$ & I,018 (83.8) & 0.390 \\
\hline Erythema & $154(65.0)$ & $587(48.3)$ & $<0.001$ \\
\hline Bleb & $133(56.1)$ & 489 (40.3) & $<0.001$ \\
\hline Necrosis & $73(30.8)$ & $317(26.1)$ & 0.149 \\
\hline Gangrene & $8(3.4)$ & $29(2.4)$ & 0.368 \\
\hline Severe pain & $222(93.7)$ & 1,045 & 0.001 \\
\hline Site of wound & & & 0.384 \\
\hline Head and neck & I (0.4) & $5(0.4)$ & \\
\hline Trunk & $7(3.0)$ & $19(1.6)$ & \\
\hline Upper limb & $47(19.8)$ & $213(17.5)$ & \\
\hline Lower limb & $175(73.9)$ & $952(78.3)$ & \\
\hline Fournier's gangrene & $6(2.5)$ & $23(1.9)$ & \\
\hline Multiple sites & $\mathrm{I}(0.4)$ & $3(0.3)$ & \\
\hline Hospital & & & 0.718 \\
\hline Chiang Rai & $|2|(5||)$. & $654(53.8)$ & \\
\hline Kamphaeng Phet & $95(40.1)$ & $455(37.5)$ & \\
\hline Phayao & $21(8.8)$ & $106(8.7)$ & \\
\hline
\end{tabular}

Notes: values are $\mathrm{n}(\%)$. *Some variables have missing data, therefore, the total number of patients in each group maybe different from the number that shown in the title. Abbreviation: BMI, body mass index.

(57.6\% versus $50.1 \%)(P=0.005)$. Moreover, the number of females who had underlying diabetes or heart disease was significantly higher than that for males, as shown in Table 5.

All variables were analyzed by univariable risk regression analysis, as shown in Table 6, and the characteristics and clinically significant variables, such as necrosis, diabetes and all statistically significant variables $(P$-value $<0.05)$ in the univariable model were included in the multivariable analysis model. The step backward elimination method of multivariable risk regression analysis was used to identify independent predictive factors of severe sepsis, as shown in Table 7. The results demonstrated that the characteristics related to severe sepsis were: female (relative risk $[R R]=1.51$, $95 \% \mathrm{CI}=1.04-2.20, P=0.03)$, age $\geq 60$ year $(\mathrm{RR}=1.25,95 \%$ $\mathrm{CI}=0.98-1.61, P=0.076)$, diabetes mellitus $(\mathrm{RR}=1.40,95 \%$ $\mathrm{CI}=1.25-1.58, P<0.001)$, chronic heart disease $(\mathrm{RR}=1.31$, $95 \% \mathrm{CI}=1.15-1.49, P<0.001)$, hemorrhagic bleb $(\mathrm{RR}=1.47$, $95 \% \mathrm{CI}=1.32-1.63, P<0.001)$, skin necrosis $(\mathrm{RR}=1.45$, $95 \% \mathrm{CI}=1.34-1.57, P<0.001)$, and serum protein $<6 \mathrm{~g} / \mathrm{dL}$ $(\mathrm{RR}=2.67,95 \% \mathrm{CI}=1.60-4.47, P<0.001)$.

\section{Discussion}

In northern Thailand, the major occupations are farmers and laborers who have poor hygiene practices and low education; therefore, appropriate wound care can be a common problem and has become the leading cause of adverse events among NF patients.

Previously, many studies have reported the risk factors for mortality or morbidity in NF patients and found that female sex, advanced age, underlying heart disease, diabetic mellitus, liver cirrhosis, and signs and symptoms such as low systolic blood pressure, hemorrhagic bullae, skin necrosis, or gas gangrene/crepitus, large body surface area, renal insufficiency (serum creatinine $>2 \mathrm{mg} / \mathrm{dL}$ ), elevated blood lactate level, hyponatremia, longer time from admission to first debridement, type of organism, leukocytosis, acidosis, and hypoproteinemia or hypoalbuminemia were all risk factors of morbidity and severe sepsis. However, these studies had no definite conclusion, and the sample size of each study was quite low (67-472 cases). ${ }^{1,6,13,18,19,24-28}$

$\mathrm{NF}$ is frequently associated with severe sepsis and rapid death. The overall severe sepsis rate for NF was $16.3 \%$ in this study, lower than that reported in other studies. ${ }^{3,12,13}$ Huang et $\mathrm{al}^{13}$ reported the overall rate of bacteremia was $23.7 \%$ because patients had not received antimicrobial therapy in the time at the emergency room, this lead to the high rate of bacteremia. In our cohort, all patients were assessed by emergency physicians and treated with broad-spectrum antibiotics in the emergency room, and this may have caused the low rate of severe sepsis.

This study found that the clinical profiles related to severe sepsis were female sex, diabetes, chronic heart disease, serum protein $<6 \mathrm{~d} / \mathrm{dL}$, hemorrhagic bleb, and skin necrosis. Huang et $\mathrm{l}^{13}$ reported that bacteremia was a frequent complication of NF, presenting in $23.7 \%$ of 472 patients. 
Table 4 Laboratory findings, vital sign measurements, and outcomes in patients with necrotizing fasciitis, with severe sepsis and without severe sepsis $(n=I, 452)$

\begin{tabular}{|c|c|c|c|}
\hline Characteristics & $\begin{array}{l}\text { Severe sepsis } \\
(n=237)\end{array}$ & $\begin{array}{l}\text { Without severe sepsis } \\
(n=I, 215)\end{array}$ & $P$-value \\
\hline \multicolumn{4}{|l|}{ Laboratory on admission } \\
\hline WBC $\left(/ \mathrm{mm}^{3}\right)$ & $\mid 7,755.7 \pm 10,808.7$ & $16,897.8 \pm 8,782.5$ & 0.609 \\
\hline PMN (\%) & $85.5 \pm 10.2$ & $81.5 \pm 11.9$ & $<0.00$ I \\
\hline Creatinine (mg/dL) & $2.9 \pm 1.7$ & $1.7 \pm 1.3$ & $<0.00$ I \\
\hline Bicarbonate $(\mathrm{mmol} / \mathrm{L})$ & $17.2 \pm 5.4$ & $22.7 \pm 4.6$ & $<0.00 \mathrm{I}$ \\
\hline Total protein $(\mathrm{g} / \mathrm{dL})$ & $5.7 \pm 1.0$ & $6.6 \pm 1.0$ & $<0.00 \mathrm{I}$ \\
\hline \multicolumn{4}{|l|}{ Laboratory $48-72$ hours } \\
\hline WBC $\left(/ \mathrm{mm}^{3}\right)$ & $16,462.0 \pm 8,182.7$ & $13,509.9 \pm 7,700.0$ & $<0.00 \mathrm{I}$ \\
\hline PMN (\%) & $84.5 \pm 12.8$ & $76.2 \pm 14.5$ & $<0.001$ \\
\hline Creatinine $(\mathrm{mg} / \mathrm{dL})$ & $2.8 \pm 1.9$ & $1.9 \pm 1.6$ & $<0.001$ \\
\hline Bicarbonate $(\mathrm{mmol} / \mathrm{L})$ & $23.4 \pm 28.6$ & $22.4 \pm 5.1$ & 0.002 \\
\hline Total protein $(\mathrm{g} / \mathrm{dL})$ & $5.2 \pm 1.2$ & $6.2 \pm 1.0$ & $<0.00$ I \\
\hline \multicolumn{4}{|l|}{ Vital sign on admission } \\
\hline Body temp $\left({ }^{\circ} \mathrm{C}\right)$ & $37.2 \pm 1.0$ & $37.3 \pm 0.9$ & 0.183 \\
\hline Pulse (/minute) & $96.6 \pm 17.2$ & $89.6 \pm 14.6$ & $<0.00 \mathrm{I}$ \\
\hline Respiratory rate (/minute) & $21.5 \pm 5.1$ & $20.3 \pm 1.7$ & $<0.00$ I \\
\hline Systolic blood pressure $(\mathrm{mmHg})$ & $103.5 \pm 26.2$ & $120.6 \pm 22.5$ & $<0.00$ I \\
\hline Diastolic blood pressure $(\mathrm{mmHg})$ & $62.2 \pm 15.8$ & $72.2 \pm 13.5$ & $<0.001$ \\
\hline \multicolumn{4}{|l|}{ Vital sign $48-72$ hours } \\
\hline Body temp $\left({ }^{\circ} \mathrm{C}\right)$ & $37.5 \pm 1.1$ & $37.2 \pm 0.7$ & $<0.001$ \\
\hline Pulse (/minute) & $96.0 \pm 19.6$ & $86.1 \pm 12.3$ & $<0.00$ I \\
\hline Respiratory (/minute) & $17.9 \pm 8.0$ & $19.9 \pm 2.6$ & $<0.00 \mathrm{I}$ \\
\hline Systolic blood pressure $(\mathrm{mmHg})$ & || $7 .| \pm 2| .4$ & $121.3 \pm 16.7$ & 0.002 \\
\hline Diastolic blood pressure $(\mathrm{mmHg})$ & $69.0 \pm 14.6$ & $73.8 \pm 10.5$ & $<0.00$ I \\
\hline \multicolumn{4}{|l|}{ Treatment and outcome } \\
\hline I\&D & $6(2.5)$ & $38(3.1)$ & 0.836 \\
\hline Debridement & $152(64.1)$ & $796(65.5)$ & 0.709 \\
\hline Fasciotomy & $95(40.1)$ & $525(43.3)$ & 0.389 \\
\hline Amputation & $32(13.5)$ & $95(7.8)$ & 0.008 \\
\hline Antibiotic use in admission date & & & 0.052 \\
\hline Cephalosporin + clindamycin & $81(34.2)$ & $409(33.7)$ & \\
\hline Cefazolin + cloxacillin + clindamycin & $21(8.9)$ & $54(4.5)$ & \\
\hline Cephalosporin + cloxacillin & $16(6.8)$ & $46(3.8)$ & \\
\hline Cloxacillin + clindamycin & $25(10.6)$ & $189(15.6)$ & \\
\hline Augmentin & $16(6.8)$ & $164(13.5)$ & \\
\hline Cloxacillin & $12(5.1)$ & $142(\mid 1.7)$ & \\
\hline Clindamycin & $9(3.8)$ & $38(3.1)$ & \\
\hline Other & $57(24.1)$ & $17 \mid(14.1)$ & \\
\hline \multicolumn{4}{|l|}{ Activity } \\
\hline Broad-spectrum antibiotic & $126(53.2)$ & $539(44.4)$ & 0.015 \\
\hline In-hospital mortality rate & $165(69.6)$ & $66(5.5)$ & $<0.00$ I \\
\hline Entire 28 days mortality rate & $18(7.6)$ & $2(0.2)$ & \\
\hline Length of hospitals stay (days) Median (IQR) & $9(3-17)$ & $8(5-14)$ & 0.805 \\
\hline
\end{tabular}

Note: Values are mean \pm standard deviation or $\mathrm{n}(\%)$.

Abbreviations: I\&D, incision and drainage; PMN, polymorphonuclear neutrophils; WBC, white blood cell count; IQR, interquartile range.

They found predictors of mortality involving NF included cirrhosis, subcutaneous emphysema, Aeromonas infection, age older than 60 years, band neutrophils, neutrophils greater than $10 \%$, activated partial thromboplastin time greater than 60 seconds, bacteremia, and serum creatinine level greater than $2 \mathrm{mg} / \mathrm{dL}$.
Tsai et a $\mathrm{l}^{29}$ carried out a study involving 143 patients with NF and found that lower systolic blood pressure, lower total and segmented leukocyte counts, higher banded leukocyte counts, and lower serum albumin levels could predict mortality.

The results of this study revealed that in NF patients, females had significantly higher risk of severe sepsis 
Table 5 Subgroup analysis of age and underlying between male and female in patients with necrotizing fasciitis $(n=I, 438-I, 45 I)$

\begin{tabular}{|c|c|c|c|}
\hline Characteristics & Male & Female & $P$-value \\
\hline Age (year) & & & 0.005 \\
\hline$\geq 60$ & $406(50.1)$ & $361(57.6)$ & \\
\hline$<60$ & 405 (49.9) & $266(42.4)$ & \\
\hline Underlying & & & $<0.001$ \\
\hline \multicolumn{4}{|l|}{ Diabetes } \\
\hline Yes & $182(22.3)$ & $195(30.9)$ & \\
\hline No & $636(77.7)$ & $437(69.1)$ & \\
\hline Heart disease & & & 0.011 \\
\hline Yes & $39(4.8)$ & $5 I(8 . I)$ & \\
\hline No & 778 (95.2) & 580 (91.9) & \\
\hline Renal disease & & & 0.086 \\
\hline Yes & $30(3.7)$ & $13(2.1)$ & \\
\hline No & $787(96.3)$ & 620 (97.9) & \\
\hline Cirrhosis & & & $<0.001$ \\
\hline Yes & $45(5.5)$ & $\mathrm{II}(\mathrm{I} .7)$ & \\
\hline No & $773(94.5)$ & $622(98.3)$ & \\
\hline Hypertension & & & $<0.001$ \\
\hline Yes & $243(29.7)$ & $269(42.5)$ & \\
\hline No & $575(70.3)$ & $364(57.5)$ & \\
\hline Gout & & & $<0.001$ \\
\hline Yes & $113(13.8)$ & $26(4.1)$ & \\
\hline No & 705 (86.2) & 607 (95.9) & \\
\hline
\end{tabular}

than males. In the subgroup analysis, we found that females had more advanced age than males; the number of females $\geq 60$ years was higher than that of males $(57.6 \%$ versus $50.1 \%)(P=0.005)$. Moreover, the number of females who had underlying diabetes or heart disease were significantly higher than for males $(30.9 \%$ versus $22.3 \%$ $[P<0.001]$ and $8.1 \%$ versus $4.8 \%$ [ $P=0.011]$, respectively). These results were similar to those reported in the study of Elliott et a $1^{18}$ demonstrating that being female and having advanced age increased the risk of mortality. However, a few studies showed that occurrence among females showed no statistically significant difference. ${ }^{3,13,19}$ Having diabetes and chronic heart disease also increased the risk of severe sepsis, due to low immunity. The low immunity could be caused by tissue ischemia from the peripheral vascular compromise, which decreases phagocytosis; moreover, hyperglycemia can promote bacterial growth. ${ }^{1,30,31}$ Underlying conditions such as diabetes mellitus and cutaneous gangrene with evidence of sepsis on admission were associated with amputation as presented by Dworkin et al; ${ }^{1}$ however, other studies found that underlying disease had no effect on the risk of amputation. ${ }^{3,18}$ Our study found that gout was seemingly related with severe sepsis in univariable analysis but was not associated with severe sepsis in the multivariable model, as found in previous study. ${ }^{32}$
Clinical characteristics such as hemorrhagic bleb $(\mathrm{RR}=1.47,95 \% \mathrm{CI}=1.32-1.63, P<0.001)$ and skin necrosis ( $\mathrm{RR}=1.45,95 \% \mathrm{CI}=1.34-1.57, P<0.001)$ on admission increase the risk of severe sepsis. The traumatized skin in these conditions allows easy access for bacteria, and then the bacteria multiply swiftly within the subcutaneous tissue and fasciae. Infection also spreads to venous and lymphatic channels, resulting in ischemia and gangrene; the spread of bacteria results in thrombosis of the blood vessels, and nerve, skin, and epidermis damage, leading to tissue edema and possible progression to hemorrhagic bleb. ${ }^{3,8}$ In previous studies, ${ }^{16,33}$ the presence of hemorrhagic bleb and skin necrosis were seen in the later stages of NF. In addition, infection with toxinproducing bacteria can result in sepsis and multiple organ failure. ${ }^{33-36} \mathrm{Hsiao}$ et $\mathrm{al}^{25}$ reported that hemorrhagic bleb was an independent predictor of mortality in patients with NF. This means that NF patients presenting hemorrhagic bleb on admission have a poor prognosis of survival.

This study also found that total protein levels $<6 \mathrm{~g} / \mathrm{dL}$ increases the risk of severe sepsis. Proteins are one of the most important factors for the tissue healing process and for hormonal and immunological functions. Patients who have serum total protein $<6 \mathrm{~g} / \mathrm{dL}$ may have an association with malnutrition, nephrotic syndrome, chronic renal failure, or severe liver disease and may have an increased risk of severe sepsis. Previous studies ${ }^{26,37}$ have demonstrated that albumin levels in the plasma, reflecting the patient's nutritional status and serum albumin concentration, were a better predictor of surgical outcomes than were most preoperative patient characteristics. Provision of sufficient nutritional support reduced the progression to organ failure and improved outcome.

In clinical practice, antibiotic resistance is one of the most important universal problems. The prevalence of drug resistance differs from place to place. Previous studies have reported risk factors for drug resistance were long-term use of antibiotics, dose antibiotic usage, prolonged hospital stay, and underlying diabetes. ${ }^{38-40}$ The best strategies for prevention and control of antibiotic drug resistance are optimizing antibiotic usage and infection control. The pathogens most commonly found to cause of NF are $S$. aureus and S. pyogenes. Therefore, MRSA and erythromycin-resistant S. pyogenes might occur and cause problematic choices of antibiotic use. ${ }^{38}$ In this study, the incidence of MRSA and ESBL producing strains isolates of $E$. coli and $K$. pneumonia infection were high in patients with severe sepsis, however, there were no statistically significant differences between the severe sepsis and the non-severe sepsis group. The risk factors for MRSA infection according to previous studies ${ }^{38-40}$ 
Table 6 Data shown univariable risk regression analysis of severe sepsis demonstrated by risk ratio, $95 \%$ confidence interval and $P$-value

\begin{tabular}{|c|c|c|c|}
\hline Risk factors & $\mathbf{R} \mathbf{R}$ & $95 \% \mathrm{Cl}$ & P-value \\
\hline Female & 1.30 & $0.86-1.98$ & 0.213 \\
\hline Age $\geq 60$ & 1.78 & $1.42-2.24$ & $<0.001$ \\
\hline $\mathrm{BMI} \leq 18.50$ & 0.89 & $0.6 \mathrm{I}-1.3 \mathrm{I}$ & 0.556 \\
\hline $\mathrm{BMI} \geq 30.00$ & 1.13 & $0.59-2.17$ & 0.720 \\
\hline Primary education & 0.66 & $0.58-0.75$ & $<0.001$ \\
\hline Secondary education & 0.40 & $0.14-1.10$ & 0.075 \\
\hline Bachelor's degree and more & 1.11 & $2.3 I-5.33$ & $<0.001$ \\
\hline Elderly who stay at home & $\mathrm{I} .40$ & $1.21-1.64$ & $<0.001$ \\
\hline Famers/labors & 0.77 & $0.68-0.87$ & $<0.001$ \\
\hline Official & 0.58 & $0.35-0.96$ & 0.033 \\
\hline Diabetes & 1.19 & $0.79-1.78$ & $0.40 \mathrm{I}$ \\
\hline Heart disease & 2.12 & $1.83-2.44$ & $<0.001$ \\
\hline Renal disease & 1.90 & $0.97-3.73$ & 0.062 \\
\hline Cirrhosis & 1.57 & $0.8 \mathrm{I}-3.0 \mathrm{I}$ & 0.180 \\
\hline Hypertension & 1.51 & $1.3 \mathrm{I}-1.74$ & $<0.001$ \\
\hline Gout & 1.86 & $|.72-2.2|$ & $<0.001$ \\
\hline Chronic alcoholism & 1.11 & $0.85-1.45$ & 0.458 \\
\hline Swell & 0.87 & $0.59-1.29$ & 0.494 \\
\hline Erythema & 1.78 & I. $17-2.70$ & 0.007 \\
\hline Bleb & I.7I & $1.40-2.09$ & $<0.001$ \\
\hline Skin necrosis & 1.21 & $1.06-1.38$ & 0.005 \\
\hline Gangrene & 1.34 & $0.95-1.88$ & 0.099 \\
\hline Severe pain & 2.15 & $1.74-2.65$ & $<0.001$ \\
\hline Head and neck & 1.02 & $0.14-7.36$ & 0.983 \\
\hline Trunk & 1.67 & $1.32-2.12$ & $<0.001$ \\
\hline Upper limb & 1.13 & $0.89-1.14$ & 0.305 \\
\hline Lower limb & 0.81 & $0.77-0.86$ & $<0.001$ \\
\hline Fournier's gangrene & 1.27 & $0.87-1.87$ & 0.213 \\
\hline Multiple site & 1.53 & $0.7 \mathrm{I}-3.34$ & 0.280 \\
\hline Total protein $<6$ (g/dL) & 2.97 & $2.09-4.21$ & $<0.001$ \\
\hline Broad-spectrum antibiotic & 1.33 & $1.08-1.65$ & 0.007 \\
\hline
\end{tabular}

Abbreviations: $\mathrm{BP}$, blood pressure; $\mathrm{BMI}$, body mass index; $\mathrm{Cl}$, confidence interval; nd, not defined; PMN, polymorphonuclear neutrophils; RR, relative risk ratio; WBC, white blood cell.

are elderly patients with diabetes mellitus (five cases), longterm use of antibiotics and prolonged hospital stay in ICU (four cases), and having history of previous operation (three cases). Because of the low incidence of MRSA and ESBL infection in this study, we could not identify statistically significant risk factors for these infections, which were mentioned in previous reports..$^{38-40}$

One of the most important determinants of mortality and morbidity is the delay of surgical intervention after admission. Early diagnosis associated with early surgical intervention and antibiotic treatments are mainstays in the treatment of NF. Previous studies reported that delayed operation for debridement was associated with increased mortality rates. ${ }^{3,8,18}$ Unfortunately, the timing of surgical variables was not available in this study because our study was a retrospective nature and some important variables were omitted from the medical records. However, Salvador et $\mathrm{a}^{26}$ reported that a delay in debridement of over 24 hours after admission was not associated with increased risk for mortality. Regarding antibiotic treatment, this study found that only $45.8 \%$ (665 in 1,542) of patients received broad-spectrum antimicrobial therapy. The possible reason was missed diagnosis at the time of admission, as cellulitis is quite difficult to distinguish at the early stage of NF. However, from multivariable analysis, antibiotic used was not a predictor for severe sepsis.

According to the review literature, the prognostic tool for evaluation of the severity of NF on admission is the Laboratory Risk Indicator for Necrotizing Fasciitis (LRINEC) score. ${ }^{41}$ The LRINEC score includes six marker variables (C-reactive protein, total WBC count, hemoglobin, serum sodium, serum creatinine, and serum glucose). In addition, in critical care, a prognostic scoring system used to evaluate disease and describe morbidity is the Acute Physiology and Chronic Health Evaluation II (APACHE II) ${ }^{42}$ score. This study could not apply either of these index scores because of its retrospective design, wherein some important variable data were unavailable - because of laboratory limitations in provincial hospitals, tests such as serum C-reactive protein, arterial blood gas, and organism cultures were not performed in all cases.

Mortality rate in NF patients with severe sepsis both inhospital and over the entire 28 days were significantly higher than in patients without severe sepsis $(P<0.001)$. Thus severe sepsis was associated with increased mortality rate, similar to previous studies. ${ }^{13,18}$

Although the results of this study do not differ much from the many discussed above, the sample size of previous studies was quite low, and no definite conclusions were drawn. We developed a retrospective cohort study with a large sample size (1,452 patients) to identify risk factors for severe sepsis in NF patients. We focused on clinical history, physical examination, and laboratory findings available under the routine clinical practices and limited resources of provincial hospitals, to identify the clinical risk factors to predict severe sepsis. The results of this study are valuable because they are suitable for specific regional areas where physicians can use these risk factors to assess their patients using the limited resources that may be available at local hospitals. This is a realistic situation currently occurring in northern Thailand. However, the results of this study cannot be generalized to other parts of Thailand or to other developing countries in Asia where the development of medical resources and services, including surgical techniques and types of antibiotics, has rapidly improved. Interpretation and application of the results of this study to clinical practice should be done 
Table 7 Summarized independent predictors of severe sepsis in patients with necrotizing fasciitis using multivariable analysis generalized linear model with step backward method $(n=I, 452)$

\begin{tabular}{llll}
\hline Risk factors & RR & $\mathbf{9 5 \% ~ C l}$ & P-value \\
\hline Female & $1.5 \mathrm{I}$ & $1.04-2.20$ & 0.032 \\
Age $>60$ years & 1.25 & $0.98-1.6 \mathrm{I}$ & 0.076 \\
Diabetes & 1.40 & $1.25-1.58$ & $<0.00 \mathrm{I}$ \\
Heart disease & $1.3 \mathrm{I}$ & $1.15-1.49$ & $<0.00 \mathrm{I}$ \\
Bleb & 1.47 & $1.32-1.63$ & $<0.00 \mathrm{I}$ \\
Necrosis & $\mathrm{I} .45$ & $1.34-1.57$ & $<0.00 \mathrm{I}$ \\
Total protein $<6 \mathrm{~g} / \mathrm{dL}$ & 2.67 & $1.60-4.47$ & $<0.00 \mathrm{I}$ \\
\hline
\end{tabular}

Abbreviations: $\mathrm{Cl}$, confidence interval; $\mathrm{RR}$, relative risk ratio.

with care. Because this study used an exploratory model, all determinants played a role as predictors of the outcome, and therefore, no confounders were found in this study. The limitation of this study is its retrospective nature, and some important variables could not be extracted from medical record, as discussed above.

\section{Conclusion}

Clinical indicators for severe sepsis in patients with NF were female sex, diabetes mellitus, chronic heart disease, hemorrhagic bleb, skin necrosis, and serum protein $<6 \mathrm{~d} / \mathrm{dL}$. Thus, patients presenting with at least one of these clinical predictors should be aware of the risk of disease progression to severe sepsis, and clinicians might consider investigating or monitoring systemic involvement progressing to morbidity and mortality.

\section{Acknowledgment}

The authors wish to thank the authorities of Chiang Rai Prachanukroh Hospital, Kamphaeng Phet Hospital, and Phayao Hospital for their support. The study was partially supported by a grant from the Faculty of Medicine and the Graduate School, Chiang Mai University, Chiang Mai, Thailand.

\section{Disclosure}

The authors report no conflicts of interest in this work.

\section{References}

1. Dworkin MS, Westercamp MD, Park L, McIntyre A. The epidemiology of necrotizing fasciitis including factors associated with death and amputation. Epidemiol Infect. 2009;137(11):1609-1614.

2. Tsitsilonis S, Druschel C, Wichlas F, et al. Necrotizing fasciitis: is the bacterial spectrum changing? Langenbecks Arch Surg. 2013;398(1): 153-159.

3. McHenry CR, Piotrowski JJ, Petrinic D, Malangoni MA. Determinants of mortality for necrotizing soft-tissue infections. Ann Surg. 1995; 221(5):558-563; discussion 563-565.

4. Cheng NC, Tai HC, Tang YB, Chang SC, Wang JT. Necrotising fasciitis: clinical features in patients with liver cirrhosis. Br J Plast Surg. 2005;58(5):702-707.
5. Hongladaromp C, Chareonsil B, Phadhana-anake O. Predictors on mortality from necrotizng fasciitis in Sawanpracharak Hospital, Nakhonsawan, Thailand. Chiang Mai Medical Journal. 2009;48(4):135-142.

6. Mulla ZD, Gibbs SG, Aronoff DM. Correlates of length of stay, cost of care, and mortality among patients hospitalized for necrotizing fasciitis. Epidemiol Infect. 2007;135(5):868-876.

7. Kaul R, McGeer A, Low DE, Green K, Schwartz B. Population-based surveillance for group A streptococcal necrotizing fasciitis: Clinical features, prognostic indicators, and microbiologic analysis of seventy-seven cases. Ontario Group A Streptococcal Study. Am J Med. 1997;103(1):18-24.

8. Wong CH, Chang HC, Pasupathy S, Khin LW, Tan JL, Low CO. Necrotizing fasciitis: clinical presentation, microbiology, and determinants of mortality. J Bone Joint Surg Am. 2003;85-A(8):1454-1460.

9. Awsakulsutthi S. A retrospective review of necrotizing fasciitis in Thammasat University Hospital. J Med Assoc Thai. 2010;93 Suppl 7: S246-S253.

10. Yadav S, Verma A, Sachdeva A. Facial necrotizing fasciitis from an odontogenic infection. Oral Surg Oral Med Oral Pathol Oral Radiol. 2012;113(2):e1-e4.

11. Vayvada H, Demirdover C, Menderes A, Karaca C. Necrotising fasciitis in the central part of the body: diagnosis, management and review of the literature. Int Wound J. 2013;10(4):466-472.

12. Uthisan T. A retrospective review of 418 cases of necrotizing fasciitis in Sisaket Hospital. Srinagarind Med J. 2008;23(1):7-16.

13. Huang KF, Hung MH, Lin YS, et al. Independent predictors of mortality for necrotizing fasciitis: a retrospective analysis in a single institution. J Trauma. 2011;71(2):467-473; discussion 473.

14. Headley AJ. Necrotizing soft tissue infections: a primary care review. Am Fam Physician. 2003;68(2):323-328.

15. Lancerotto L, Tocco I, Salmaso R, Vindigni V, Bassetto F. Necrotizing fasciitis: classification, diagnosis, and management. J Trauma Acute Care Surg. 2012;72(3):560-566.

16. Wong $\mathrm{CH}$, Wang YS. The diagnosis of necrotizing fasciitis. Curr Opin Infect Dis. 2005;18(2):101-106.

17. Puvanendran R, Huey JC, Pasupathy S. Necrotizing fasciitis. Can Fam Physician. 2009;55(10):981-987.

18. Elliott DC, Kufera JA, Myers RA. Necrotizing soft tissue infections. Risk factors for mortality and strategies for management. Ann Surg. 1996;224(5):672-683.

19. Anaya DA, McMahon K, Nathens AB, Sullivan SR, Foy H, Bulger E. Predictors of mortality and limb loss in necrotizing soft tissue infections. Arch Surg. 2005;140(2):151-157; discussion 158.

20. Stevens DL, Bisno AL, Chambers HF, et al. Practice guidelines for the diagnosis and management of skin and soft tissue infections: 2014 update by the Infectious Diseases Society of America. Clin Infect Dis. 2014;59(2):e10-e52

21. Dellinger RP, Levy MM, Rhodes A, et al; Surviving Sepsis Campaign Guidelines Committee including The Pediatric Subgroup. Surviving Sepsis Campaign: international guidelines for management of severe sepsis and septic shock, 2012. Intensive Care Med. 2013;39(2): $165-228$.

22. Shrive FM, Stuart H, Quan H, Ghali WA. Dealing with missing data in a multi-question depression scale: a comparison of imputation methods BMC Med Res Methodol. 2006;6:57.

23. Myers WR. Handling missing data in clinical trials: an overview. Drug Inf J. 2000;34(2):525-533.

24. Golger A, Ching S, Goldsmith CH, Pennie RA, Bain JR. Mortality in patients with necrotizing fasciitis. Plast Reconstr Surg. 2007;119(6):1803-1807.

25. Hsiao CT, Weng HH, Yuan YD, Chen CT, Chen IC. Predictors of mortality in patients with necrotizing fasciitis. Am J Emerg Med. 2008;26(2):170-175.

26. Salvador VB, San Juan MD, Salisi JA, Consunji RJ. Clinical and microbiological spectrum of necrotizing fasciitis in surgical patients at a Philippine university medical centre. Asian J Surg. 2010;33(1):51-58.

27. Chen IC, Li WC, Hong YC, Shie SS, Fann WC, Hsiao CT. The microbiological profile and presence of bloodstream infection influence mortality rates in necrotizing fasciitis. Crit Care. 2011;15(3):R152. 
28. Kuo Chou TN, Chao WN, Yang C, Wong RH, Ueng KC, Chen SC. Predictors of mortality in skin and soft-tissue infections caused by Vibrio vulnificus. World J Surg. 2010;34(7):1669-1675.

29. Tsai YH, Huang KC, Shen SH, Hsu WH, Peng KT, Huang TJ. Microbiology and surgical indicators of necrotizing fasciitis in a tertiary hospital of southwest Taiwan. Int J Infect Dis. 2012;16(3):e159-e165.

30. Thaichinda S, Kositpantawong N. Necrotizing skin and soft-tissue infections associated with septicemia: 7 cases report and review. J Med Assoc Thai. 2008;91(1):117-123.

31. Nakayama J, Busse R. An analysis of vulvar necrotizing fasciitis in the unique and ethnically diverse Hawaiian population. Hawaii Med J. 2010;69(1):13-16.

32. Bair MJ, Chi H, Wang WS, Hsiao YC, Chiang RA, Chang KY. Necrotizing fasciitis in southeast Taiwan: clinical features, microbiology, and prognosis. Int J Infect Dis. 2009;13(2):255-260.

33. Tilkorn DJ, Citak M, Fehmer T, et al. Characteristics and differences in necrotizing fasciitis and gas forming myonecrosis: a series of 36 patients. Scand J Surg. 2012;101(1):51-55.

34. Salcido RS. Necrotizing fasciitis: reviewing the causes and treatment strategies. Adv Skin Wound Care. 2007;20(5):288-293; quiz 294.

35. Cainzos M, Gonzalez-Rodriguez FJ. Necrotizing soft tissue infections. Curr Opin Crit Care. 2007;13(4):433-439.

36. Ruiz-Tovar J, Córdoba L, Devesa JM. Prognostic factors in Fournier gangrene. Asian J Surg. 2012;35(1):37-41.
37. Gibbs J, Cull W, Henderson W, Daley J, Hur K, Khuri SF. Preoperative serum albumin level as a predictor of operative mortality and morbidity: results from the National VA Surgical Risk Study. Arch Surg. 1999; 134(1):36-42.

38. Stevens DL, Bisno AL, Chambers HF, et al. Practice guidelines for the diagnosis and management of skin and soft-tissue infections. Clin Infect Dis. 2005;41(10):1373-1406.

39. Lipsky BA, Tabak YP, Johannes RS, Vo L, Hyde L, Weigelt JA. Skin and soft tissue infections in hospitalised patients with diabetes: culture isolates and risk factors associated with mortality, length of stay and cost. Diabetologia. 2010;53(5):914-923.

40. Tacconelli E, De Angelis G, Cataldo MA, Pozzi E, Cauda R. Does antibiotic exposure increase the risk of methicillin-resistant Staphylococcus aureus (MRSA) isolation? A systematic review and meta-analysis. J Antimicrob Chemother. 2008;61(1):26-38.

41. Wong CH, Khin LW, Heng KS, Tan KC, Low CO. The LRINEC (Laboratory Risk Indicator for Necrotizing Fasciitis) score: a tool for distinguishing necrotizing fasciitis from other soft tissue infections. Crit Care Med. 2004;32(7):1535-1541

42. Knaus WA, Draper EA, Wagner DP, Zimmerman JE. APACHE II: a severity of disease classification system. Crit Care Med. $1985 ; 13(10): 818-829$.

\section{Publish your work in this journal}

Infection and Drug Resistance is an international, peer-reviewed openaccess journal that focuses on the optimal treatment of infection (bacterial, fungal and viral) and the development and institution of preventive strategies to minimize the development and spread of resistance. The journal is specifically concerned with the epidemiology of antibiotic

\section{Dovepress}

resistance and the mechanisms of resistance development and diffusion in both hospitals and the community. The manuscript management system is completely online and includes a very quick and fair peerreview system, which is all easy to use. Visit http://www.dovepress.com/ testimonials.php to read real quotes from published authors. 